\title{
Motion parallax in the perception of movement by a moving subject
}

\author{
FELIX E. GOODSON, TRACY Q. SNIDER, and JAMES E. SWEARINGEN \\ DePauw University, Greencastle, Indiana 46135
}

\begin{abstract}
This experiment was designed to study the influence of motion parallax on the perception of movement by a moving subject. Motion parallax occurs when an observer is moving in the environment. Items closer to the observer move in the direction opposite to his movements more rapidly than items further away. This is due to the fact that the angle of shift between the moving observer and objects in the environment is progressively less as distance increases. To demonstrate that motion parallax provides important cues for the perception of movement, these cues were manipulated to produce a perceptual paradox. First, a more distant item (a stimulus ball) was actually moved until its apparent motion was synchronized with nearer items (a forward plane of balls). Then the subjects were allowed to observe the stimulus ball as it was being slowed from synchrony with the forward plane of balls. Under these circumstances, the subjects reported significantly that the stimulus ball was moving forward, even though it was actually moving backward.
\end{abstract}

Even though a person may be moving, say in a car, or perhaps walking, he can make fairly accurate judgments of the movement of other items in the environment. And he can make these judgments even though irregular changes are continually occurring in the position of the eyes, head, and body. What are the cues (or cue) that provide the basis for such judgments? It is our view that motion parallax provides important cues in the perception of movement by a moving subject. Motion parallax is "the optical change of the visual field of an observer which results from a change of his viewing position" (Gibson, Gibson, Smith, \& Flock, 1959 , p. 40). When a subject moves with respect to his environment, the rate at which the projection of an object moves across the retina varies inversely with the distance of the object: Closer objects will appear to move faster and distant objects, slower (Braunstein, 1976). This can be easily demonstrated by moving one's head back and forth while observing objects at various distances.

A number of investigators (Gibson et al., 1959; Goodson, Ritter, \& Thorpe, 1978) have demonstrated that motion parallax is an important cue for depth perception, but little research has been specifically designed to study its influence on the perception of motion. It was felt that the clearest evidence that motion parallax is a cue for motion perception would be provided if subjects would perceive an item moving in a direction opposite to its actual movement when the basic factor accounting for this paradox was motion parallax.

Reprint requests should be sent to Felix Goodson, Department of Psychology, DePauw University, Greencastle, Indiana 46135.

\section{Hypothesis}

As viewed by a moving observer, a stimulus object that is being slowed from synchrony with a static foreground plane will be seen as moving forward even though it is still moving backward.

\section{METHOD}

\section{Subjects}

Twenty volunteer undergraduate students from DePauw University (10 male and 10 female) were used as subjects. All were screened for corrected or normal 20/20 vision.

\section{Apparatus}

Visual Display. A black rectangular wooden frame measuring $6 \times 12 \times 3.5 \mathrm{ft}$ provided housing for the visual display. A total of 28 gray styrofoam balls ranging in size from 1 in. to 3.5 in. were strung on four 2-1b-test clear nylon fishing lines across the front of the frame in a plane perpendicular to the subject's line of sight.

A black styrofoam ball 2.5 in. in diameter was mounted on a loop of 15-lb-test clear nylon fishing line $2 \mathrm{ft} 2 \mathrm{in}$. in back of the plane of gray balls and $15 \mathrm{in}$. in front of a plain white background. This ball was moved horizontally by a $1 / 15-\mathrm{hp}$ reversible electric motor. The speed of the movement was regulated by a variac connected to the motor.

The visual display area was framed by black curtains on each side and was illuminated by four $500-\mathrm{W}$ opaque bulbs mounted $8 \mathrm{in}$. above each of the four corners of the frame of the visual display.

Subject Transport. The subject-transport apparatus consisted of a $9 \times 2.5 \mathrm{ft}$ runway constructed of plywood. At one end, a single pulley was mounted and at the other, a double pulley. An 18-in. V-belt, attached to a cart with a chair mounted to it, moved between the two pulleys. Attached to the chair was a head restraint. Guide supports of .5 -in. wood were fixed to the runway to prevent lateral movement of the cart. The remaining pulley was connected by a 40 -in. V-belt to a tripletakedown speed-reduction unit. A .5-hp constant-torque variablespeed reversible electric motor was connected to this.

The runway was located $14 \mathrm{ft}$ from and was parallel to the 
front plane of gray balls. In this position, synchronization between the stimulus ball and the plane of gray balls was achieved when the ball was moving $2.64 \mathrm{~cm} / \mathrm{sec}$, and the chair was moving at $24 \mathrm{~cm} / \mathrm{sec}$.

\section{Procedure and Design}

The subject was blindfolded, led into the room, seated in the mobile chair, and read the following: "We are doing research in motion perception. In a moment we will remove your blindfold and allow you to view the experimental apparatus." The subject's head was then secured by a device attached to the mobile chair to eliminate lateral head movement, the blindfold was removed, and the following instructions were read: "In the following trials you will see a black ball in the visual field. It will be your job to note the movement of this ball. You will be allowed to make eight observations. You should realize that the movement will be very subtle, so you should observe carefully. After each of the observations you will be given a card on which you will check what you have observed. Remember you should check what you actually observed, not what you think the experimenter might want." The subject was then shown a response card containing the following statements: "Relative to my movement: () The ball moved in the same direction; () The ball moved in the opposite direction; ( ) I don't know." The subject was then moved back and forth once and was allowed to view the apparatus with the stimulus ball in synchrony with the plane of balls. In each case, the subject was questioned to be sure that he was able to distinguish the black stimulus ball from the other balls.

Test Trials. An eye patch was placed over one eye of each subject during all trials. Each subject was given eight trials, with the two directions of movement alternated. In Trials 2, 3, 5, 7, and 8 (the critical trials), the stimulus ball was slowed from synchronous speed and on Trials 1, 4, and 6 the stimulus ball was increased above synchronous speed. (These noncritical trials were interposed to keep the subjects from developing a response set.) Each trial was started with the stimulus ball in synchrony with the foreground plane of balls and with the room in total darkness. As soon as the subject's motion had become stabilized, the lights were turned on and the subject was allowed to observe the visual display apparatus for $3 \mathrm{sec}$ as the stimulus ball was moving out of synchrony with the forward plane of balls. In these critical trials, even though it was being slowed down, the stimulus ball was actually moving in the direction opposite that of the subject during the entire 3-sec observation period. After each trial had been completed and the chair brought to a resting position, the lights were turned on, the eye patch was removed, and the subject was given $15 \mathrm{sec}$ to make his response on the answer sheet.

\section{RESULTS}

The subjects reported on $62 \%$ of the trials that the stimulus ball was moving in the same direction that they were moving. A nonparametric Wilcoxon matchedpairs signed-ranks test was applied to the data, compared with $33.3 \%$ expected occurrence. The difference between the observed and expected frequencies was significant at the $p<.01$ level of confidence. When the data were analyzed without the "don't know" category, the difference in the predicted direction was even more dramatic: On $86 \%$ of the trials on which a judgment of motion was given, the stimulus ball was seen to be moving in the same direction as the subject.

\section{REFERENCES}

Braunstein, M. I. Depth perception through motion. New York: Academic Press, 1976.

Gibson, E. J., Gibson, J. J., Sмiтh, O. W., \& Flock, H. Motion parallax as a determinant of perceived depth. Journal of Experimental Psychology, 1959, 58, 40-51.

Goodson, F. E., RITTer, S., \& Thorpe, R. Motion parallax in depth and movement perception. Bulletin of the Psychonomic Society, 1978, 12, 349-350.

(Received for publication June 2, 1980.) 